\title{
Method for Quality Appraisal in Supply Networks
}

\author{
João Gilberto Mendes dos Reis ${ }^{1,2}$ and Pedro Luiz de Oliveira Costa Neto ${ }^{1}$ \\ ${ }^{1}$ Paulista University (UNIP), PPGEP, São Paulo, Brazil \\ politeleia@uol.com.br, betomendesreis@msn.com \\ ${ }^{2}$ Federal University of Grande Dourados (UFGD), Department Production Engineering, \\ Dourados, Brazil \\ joaoreis@ufgd.edu.br
}

\begin{abstract}
The study of supply networks or supply chains is an emerging theme in the world of Production Engineering. The complexity of how companies relate to their networks cannot be resolved through a single management strategy anymore. At the same time, quality can no longer be seen as something inherent to individual companies. This paper studies the alignment of three important aspects: product type (functional or innovative) network strategy (agile, responsive, flexible or lean), Quality Management System - QMS (Hashin Kanri, Total Quality Management, Six Sigma and / or ISO Standards). To do this developed a method that aims to check the alignment mentioned and suggest to companies the quality management system best suited to each situation. The method presented an accuracy of over $90 \%$ in its use in research conducted.
\end{abstract}

Keywords: Supply Networks, Supply Network Strategies, Quality Management Systems, Innovative and Functional Products.

\section{Introduction}

Relationships between companies have become consolidated as these understand the need to operate in networks to be able to compete in current markets. For this purpose, and also seeking to maintain competitiveness in their markets, the companies have had to appraise and also position themselves inside the supply networks, including the flow of their products and services within these chains, seeking to respond to all the demands made by the clients.

Within this context, we can also conclude that these supply networks have different strategies according to the approach adopted by this net, or, in other words, the search for the elimination of waste, the capacity to make the processes more flexible, the ability of responding to the markets and also agility in serving the volatile markets. In essence, these strategies refer to the characteristics of the products made by the chain, that can be of the innovative or functional kind.

The success of the supply networks lies in the identification of the type of product which is delivered to the consumer, as it is therefore possible to establish the correct chain strategy to be adopted and also the application of the most appropriate QMS to be used. 
In this way, this work seeks to present a method for the appraisal of quality in supply networks, that checks the alignment between these three aspects. The purpose of this method is to allow the organisations to appraise if their supply networks are using the appropriate approach in relation to the chain strategy and also the quality management system.

\section{Methodology}

Methodologically, this work has been divided into a sequence of phases, as shown below:

- First, there was a review of the relevant literature, seeking to understand the aspects and strategies that involve the supply networks, as also the concepts of quality, their applications and consequences.

- Next, a method was established to identify the functional or innovative characteristic of the product, its supply network strategy and also the most appropriate quality system for this strategy.

- Then, there was the production of a form with the questions to be aimed at the organisations and also the collection of management and accounting data from the companies.

- The fourth part was the application of the method to thirteen organisations, in order to identify the alignment between the type of product, chain strategy and quality, checking to see if this is in agreement with what the method proposes and also its discussions.

\section{$3 \quad$ Background}

\subsection{Supply Networks Strategies}

A supply network seeks, by means of a relationship between organisations, in other words suppliers and clients, to deliver their products and services to the end consumer. The process of management this Supply Networks or Supply Chains is known as Supply Chain Management (SCM).

SCM is the management of the interconnection between companies that establish relationships with each other, through upstream and downstream links between the different processes, which add value in the form of products and services for the final customer [1].

Thus, this is more than just a case of cost management, as this affects other aspects such as performance, speed and reliability of deliveries, the quality of the products and, finally, the flexibility with which the network can make adaptations [2]. At present, it is possible to divide the supply network strategies into four distinct strategies.

Lean Supply Network. The concept of lean thought consists of developing a continuous flow of value to eliminate all the waste, including the waste of time [3]. 
This thought may be brought out in the Toyota Production Systems (TPS), whose focus is on the reduction and elimination of waste [4]. TPS became known to other Japanese companies, and in the 1980s it took the West by storm, becoming known as Just in Time (JIT). One of the key characteristics of the business environment is that competition also takes place between the supply networks and not only between organisations [5]. Similarly, the elimination of waste, as also the effects of Lean Manufacturing (LM), does not occur only in one organisation but rather in a network of companies. Thus, this advancement of lean techniques for the whole network has become known as Lean Supply Network (LSN) or Lean Supply Chains (LSC).

Flexible Supply Network. Manufacturing companies, up against keen competition, have developed the skill to deal with external and internal uncertainties, making use of flexibility [6]. This is a target to be sought within organisations. The concept of flexibility, like that of Lean Production, has its main showcase of ideas in TPS, as flexibility is a constituent element of JIT. Thus, flexibility may be defined as the skill in changing or reacting with minimal loss of time [7]. A supply chain cannot be something that cannot be changed, and it is necessary that it has the ability to impart quick flexibilisation of its operations, whether of production, logistics, marketing or supplies, which is possible through the circulation of information through the different links of the chain. Thus, the use of flexibility in supply chains has created the strategy known as Flexible Supply Chain (FSC), in some cases defined as Supply Chain Flexibility (SCF) or in this paper Flexible Supply Network (FSN). The idea behind this type of strategy is the reduction of risk through the use of characteristics of flexibility throughout the network.

Responsive Supply Network. Responsiveness consists of a skill of intentionally reacting, within an appropriate time scale, to the demands and changes in the market, thus maintaining a competitive edge [8]. Responsiveness is a strategy that consists of its response time, meaning that the shorter the response time for the chain in meeting the needs of the clients, the more responsive the chain shall be. Thus, those organisations that compete in volatile markets and/or where the client is not willing to wait, can obtain a sustainable competitive advantage through the reduction of their process times, whether the processes are productive, logistic or through obtaining raw materials. What allows a network to be more responsive is the good use of the competitive advantages based on time, using systems that are responsive and fast [5]. The responsive chains are known as Responsive Supply Network (RSN) or Responsive Supply Chains (RSC).

Agile Supply Chains. Among the different supply network strategies, one may be considered the most important among them, which is the case of agile supply chains. Agility is the skill of companies involving an organisational structure, information systems, logistic processes and, in particular, knowledge management [9]. The idea of agility within the concept of SCM focuses on the context of response to the market, being led by demand, with one main characteristic being that of a shorter lead time, based on information [10]. This kind of supply chains are known as Agile Supply Network (ASN) or Agile Supply Chains (ASC). 


\subsection{Supply Chain Management Quality}

Quality can be defined as conformity with the requirements [11]. Quality cannot exist if the requirements are not met; someone could wish to have quality of life, but this would be generic were it not for the establishment of specific requirements such as appropriate income, health, education and other measurable aspects [11]. Among the different processes of quality management, we could highlight: TQM (Total Quality Management), Six Sigma, ISO Standards and Hoshin Kanri.

Feigenbaum, who is one of the most important quality gurus, says that the quality of products and services to the consumer varies according to the life cycle of the product [12]. Thus, it is possible to identity four well-defined phases: innovation, the period in which the product is innovative and the consumer's demand for quality is less due to the fact that this is an innovation being implemented; conspicuous consume, the period in which the consumer seeks the visibility of the product (beauty and aesthetic characteristics) where the demand for quality is higher than in the previous phase, but still susceptible to faults; general use, where the use of the product becomes more widespread and there is the start of complete demand for quality; and commoditisation, the stage in which the products are part of people's lives, with the sale price of the product is low and the quality demands are at a maximum, meaning that in this stage there is no tolerance of faults and defects[12].

In the study of the literature on the issue, we see that there are very few texts that study the quality of supply networks; among the works found we can mention some research that has been used to understand the theme and also for the execution of this work: [13], [14], [15], [16], [17].

\subsection{Functional and Innovative Products}

The supply networks suffer from the excess of some products and the shortage of others, through the inability to predict demand and that an effective supply chain strategy is more than just considering the nature of demand for the company products [18].

Fisher classifies the products, based on the demand standards, in two different categories [18]:

Functional Products. These are the products which satisfy basic needs of the consumer, which do not change much over time, having predictable and stable demand and long life cycles. This stability generates competition, which leads to low profit margins.

Innovative Products. These are the products which, through innovation and technology, become popular in certain periods and therefore generate, for the consumers, an additional attraction for the purchase of these products, which increases the profit margins. However, their demand is unpredictable, their life cycle is short (a matter of months) and also they suffer from imitations by other companies, which either reduce or eliminate the original competitive edge, meaning that the company shall have to live based on cycles of innovations. 


\section{Method Development}

The method that has been developed for research consisted of four phases:

1. Research of Data: The first stage of the method

is that of collecting the input data. In this work, the data were collected through a specific form assigned to managers of participating companies and also data available on the market, about participating companies, such as management reports and accounting spreadsheets.

2. Identification of Products: The identification of whether the products are functional or innovative is made through the use of Table 1 , where the corresponding answer is marked for each column. A number of five or greater for the column of functional products or the column of innovative products allows one to identify if the product is functional or innovative.

Table 1. Innovative x functional products

\begin{tabular}{|c|c|c|c|}
\hline Item & Features & Functional Products & Innovative Products \\
\hline 1 & Aspects of demand & Predictable & Unpredictable \\
\hline 2 & Product life cycle & More than 2 years & Up to 2 years \\
\hline 3 & Contribution margin & Up to $20 \%$ & More than $20 \%$ \\
\hline 4 & Product variety & Low & High \\
\hline 5 & $\begin{array}{l}\text { Average margin of error in the } \\
\text { forecast at the time production is } \\
\text { committed }\end{array}$ & Up to $10 \%$ & More than $10 \%$ \\
\hline 6 & Average stockout rate & Up to $2 \%$ & More than $2 \%$ \\
\hline 7 & $\begin{array}{l}\text { Average forced end-of-season } \\
\text { markdown as percentage of full } \\
\text { price }\end{array}$ & Up to $10 \%$ & More Than $10 \%$ \\
\hline 8 & $\begin{array}{l}\text { Lead time required for made-to- } \\
\text { order products }\end{array}$ & 3 weeks or more & Up to 2 weeks \\
\hline
\end{tabular}

3. Identification of chain strategy: Once the nature of the products has been identified, then the third stage seeks to establish the chain strategy to be used for this type of product. Once again making use of the data collected about uncertainty in supplies and also of demand, there is the application of the Table 2 which is based in the observations made by Lee [19], thus finding the most appropriate chain strategy. 
Table 2. Supply uncertainty x demand uncertainty

\begin{tabular}{cccc}
\hline & \multicolumn{2}{c}{ Demand Uncertainty } \\
& $\begin{array}{c}\text { Low (Functional } \\
\text { Products) }\end{array}$ & $\begin{array}{c}\text { High (Innovative } \\
\text { Products) }\end{array}$ \\
\hline & Low (Stable Process) & Lean Supply Network & $\begin{array}{c}\text { Responsive Supply } \\
\text { Network }\end{array}$ \\
& High (Evolving Process) & $\begin{array}{c}\text { Flexible Supply } \\
\text { Network }\end{array}$ & Agile Supply Network \\
\hline
\end{tabular}

4. Establish a correlation between the variables and also identify the quality management system which is suitable for the supply chain: Once the type of product and the chain strategy have been identified, the types of products are linked to the supply chain strategy, the quality stage and the QMS. The result shows the ideal quality system to be applied (Table 3).

Table 3. Relationship between type of product, supply chain strategy, quality stage and QMS

\begin{tabular}{ccccc}
\hline Items & ASN & RSN & FSN & LSN \\
\hline $\begin{array}{c}\text { Type of } \\
\text { Product } \\
\text { Supply } \\
\text { Network } \\
\text { Strategy }\end{array}$ & Innovative & Innovative & Functional & Functional \\
$\begin{array}{c}\text { Stage of } \\
\text { Quality }\end{array}$ & Annovation & Responsive & Flexible & Lean \\
& & Consume & General Use & Commoditization \\
& & & Six Sigma & \\
Quality & Hoshin & Hoshin Kanri & Total Quality & Six Sigma \\
Management & Kanri & Total Quality & Management & $\begin{array}{c}\text { Total Quality } \\
\text { System Hint }\end{array}$ \\
& & Management & $\begin{array}{c}\text { Standards ISO } \\
\text { (Second Part }\end{array}$ & Standards ISO \\
& & & Audit) & (Third Part Audit) \\
\hline
\end{tabular}

\section{Discussion and Research Results}

The method presented was applied to thirteen organisations from several different segments: one manufacturer of electrical equipment, one of plastic products, two of technology, one of foodstuffs, two of metallurgy and steel production, one from the automotive industry, two from the medical and diagnostic equipment segment and three producers of electronic goods. The field research took place in the second half of 2011. To check if the products were functional or innovative at the companies, 
products were chosen for each institution with similar characteristics, as the method requires the identification of the product to be analysed. Applying the concepts of Table 1, nine companies presented functional products, while only four were dealing with innovative products.

Once the type of product was identified, there was then the assessment of the most appropriate network strategy for each company, listing the uncertainties of demand and supply, and also checking the characteristics of the product, based on Table 2.

Thus, it was confirmed that $46 \%$ of the companies should use a lean strategy, $23 \%$ should use a flexible strategy, $15.5 \%$ a responsive strategy and another $15.5 \%$ an agile strategy.

In the form, there was the inclusion of one question in order to identify if the respondents perceived the type of supply chain strategy adopted by the organisations. The results showed that only two respondents managed to precisely identify the chain strategy used by their supply chain.

In relation to the QMS that the companies adopt, these have been analysed from two different angles, first considering the organisation under study and then considering this company's suppliers of raw materials, equipment and services.

The companies have said that they apply the ISO 9001:2008 standard. Evidently this standard is well known throughout the world and hence it is applied by most companies. In many segments, this standard is even mandatory for the suppliers. The other quality management systems were mentioned in an equivalent way, but none of them was present in more than $30 \%$ of the sample. Some organisations say that they use other specific quality assurance systems for the segment in which they are present. In all, 77\% of the companies researched consider their management system to be excellent or good.

The second analysis was in relation to the quality management systems which they demanded from their suppliers of raw materials, equipment and services. To make sure of the quality of suppliers of products and services, the companies surveyed mostly used internal systems for the certification of suppliers and also created indices for the monitoring thereof. Other companies used ISO certification as a way of ensuring this quality. Only two companies said that they had distinctive systems to make sure of the quality of suppliers of products (raw materials and equipment) and service suppliers. For the first situation, they use ISO 9001:2008 while for the second situation they use performance indicators.

Finally, in relation to the correct alignment between product type, chain strategy and QMS, it was observed that the most appropriate systems to be implemented for the chain strategy of each organisation are not being applied in practice, there being a predominance of the application of ISO, regardless of the chain strategy used. TQM and Six Sigma are sometimes applied together and other times individually, but there is no prevalence for the companies as a whole. In relation to Hashin Kanri, we see that most companies are unaware of its scope, and this is directly reflected in the low usage of this type of QMS.

Through the data collected in the research, it was possible to reach the conclusion that, for the companies dealing with functional products, there is a correct application of QMS, in relation to the type of product made and the chain strategy to be used. However, in the case of innovative products there is some difficulty in using the correct QMS due to the high degree of uncertainty to which the organisations have been subjected and also the lack of awareness of the most efficient quality techniques for this type of stage, as mentioned by Feigenbaum [12] and demonstrated in this work. 


\section{Conclusions}

This work developed a method to check the alignment between type of product, chain strategy and quality management system which can allow organisations, on achieving their correct alignment, to obtain sustainable competitive advantage.

\section{References}

1. Slack, N., Chambers, S., Johnston, R.: Operations management. Prentice-Hall, Upper Saddle River (2010)

2. Corrêa, H.L.: Management supply networks. Atlas, São Paulo (2010) (in Portuguese)

3. Naylor, J.B., Mohamed, M.N., Berry, D.: Leagility: integration the lean and agile manufacturing paradigms. International Journal Producton Economics 62, 107-118 (1999)

4. Agarwal, A., Shankar, R., Tiwari, M.K.: Modeling the metrics of lean, agile and leagile supply chain. European Journal of Operations Research 173, 211-225 (2006)

5. Christopher, M.: Logistics \& supply chain management. Prentice-Hall, Harlow (2005)

6. Gong, Z.: An economic evaluation model of supply chain flexibility. European Journal of Operation Research 184, 745-758 (2008)

7. Upton, D.M.: The management of manufacturing flexibility. California Management Review 36, 72-89 (1994)

8. Holweg, M.: The three dimensions of responsiveness. International Journal of Operations and Production Management 25, 603-622 (2005)

9. Christopher, M.: The agile supply chain: competing in volatile markets. International Marketing Management 29, 37-44 (2000)

10. Christopher, M., Lowson, R., Peck, H.: Creating agile supply chains in fashion industry. International Journal of Retail and Distribution Management 32, 367-376 (2004)

11. Crosby, P.B.: Quality is investment. José Olympio, Rio de Janeiro (1994) (in Portuguese)

12. Feigenbaum, A.V.: Total quality control. Makron Books, São Paulo (1994) (in Portuguese)

13. Robinson, C.J., Malahotra, M.K.: Defining the concept of supply chain quality management and its relevance academic and industrial practice. International Journal of Production Economics 96, 315-337 (2005)

14. Sila, I., Ebrahimpour, M., Birkholz, C.: Quality in supply chains: an empirical analysis. Supply Chain Management 6, 491-502 (2006)

15. Foster Jr., S.T.: Towards an understanding of supply chain quality management. Journal of Operations Management 26, 461-467 (2008)

16. Kaynak, H., Hartley, A.: A replication and extension of quality management into supply chain. Journal of Operations Management 26, 468-489 (2008)

17. Carmignani, G.: Supply Chain and Quality Management. Business Process Management Journal 15, 395-407 (2009)

18. Fisher, M.: What is the right supply chain for your product? Harward Business Review, 105-115 (March-April 1997)

19. Lee, H.L.: Aligning supply chain strategies with product uncertainties. California Management Review 44, 105-119 (2002) 